\title{
Infecção por Salmonella enterica em suínos criados em um sistema integrado de produção do sul do Brasil
}

[Salmonella infection in pigs raised in a multiple-site swine production system from southern Brazil]

\author{
L.E. Silva ${ }^{1}$, C.P. Gotardi ${ }^{1}$, R. Vizzotto ${ }^{2}$, J.D. Kich ${ }^{2}$, M.R.I. Cardoso ${ }^{1 *}$ \\ ${ }^{1}$ Faculdade de Veterinária - UFRGS \\ Av. Bento Gonçalves, 9090 \\ 91450-000 - Porto Alegre, RS \\ ${ }^{2}$ Embrapa Suínos e Aves - Concórdia, SC
}

\begin{abstract}
RESUMO
Avaliou-se a difusão da infecção em um rebanho com prévio isolamento de Salmonella sp, em que leitões, individualmente identificados, foram amostrados para excreção fecal de Salmonella sp e sorologia do nascimento ao abate. Da mesma forma, amostras de ração e suabes do ambiente foram coletados durante o estudo para pesquisa de Salmonella sp A pesquisa de anticorpos foi realizada pela utilização de ELISA-LPS de Salmonella Typhimurium. Os leitões foram negativos na análise bacteriológica e na sorologia até a fase de creche, tornando-se positivos para Salmonella sp no início da terminação. Nessa amostragem, 28,6\% dos animais foram soropositivos e 75\% estavam excretando Salmonella sp nas fezes. Ao abate, a percentagem de animais soropositivos $(76,9 \%)$ aumentou, enquanto o isolamento de Salmonella sp ocorreu em 19,2\% dos suínos. Foi isolada Salmonella sp de duas das 26 amostras de ração. A contaminação do ambiente da terminação ocorreu apenas após o alojamento dos animais. Concluiu-se que a terminação foi o ponto crítico de contaminação desse lote, sendo a ração uma fonte de contaminação.
\end{abstract}

Palavras-chave: suíno, estudo longitudinal, Salmonella, ELISA

\begin{abstract}
Salmonella diffusion in a swine production system, previously identified as Salmonella-positive, was evaluated. A cohort of pigs was followed from farrowing to slaughtering. Samples of feces, intestinal content, mesenteric lymph nodes and blood were taken from the animals throughout the study. In addition, feed samples and environmental swabs were done for the isolation of Salmonella sp. Serum was submitted to a Salmonella Typhimurium LPS-ELISA. Piglets were negative in bacteriological and serological tests until the nursery phase, but became Salmonella positive in the early finishing. On this phase, 28.6\% of finishers were seropositive and 75\% were shedding Salmonella in feces. At slaughtering, the seropositivity (76.9\%) was higher than in the early finishing, but Salmonella was isolated only from $19.2 \%$ of the sampled pigs. Two out of 26 feed samples were Salmonella positive. Contamination of the finishing site environment was detected only when the animals were housed. It was concluded that the termination phase was critical for the contamination of this cohort of pigs, being the feed a source of contamination.
\end{abstract}

Keywords: swine, longitudinal study, Salmonella, ELISA

Recebido em 30 de agosto de 2004

Aceito em 6 de março de 2006

*Autor para correspondência (corresponding author)

E-mail: mcardoso@ufrgs.br

Apoio: $\mathrm{CNPq}$ 


\section{INTRODUÇÃO}

Estudos realizados no Rio Grande do Sul encontraram alta prevalência de animais portadores de Salmonella sp na terminação (Bessa et al., 2004) demonstrando, também, que há implicação na contaminação das carcaças e do produto final (Bandeira, 2003; Castagna et al., 2004).

A partir da crescente ênfase na redução da contaminação de produtos cárneos após o processamento, tem-se estimulado a identificação de medidas para reduzir ou eliminar esse microrganismo antes do abate (Funk et al., 2001), uma vez que a redução das taxas de infecção pré-abate resulta em aumento da segurança dos produtos suínos (Hurd et al., 2002). Assim, além do status sanitário das granjas, o transporte e a espera pré-abate têm sido apontados como pontos críticos de contaminação por Salmonella sp (Rostagno et al., 2003). Muitos pesquisadores também têm atribuido risco significativo de introdução de Salmonella sp na cadeia produtiva através da ração e da entrada de animais portadores (Stärk et al., 2002).

Embora a prevalência de Salmonella sp possa ser medida por testes sorológicos e bacteriológicos (van der Gaag et al., 2004) a partir de grupos de animais de diferentes idades (Stege et al., 2000), estudos transversais, que oferecem estimativas pontuais de prevalência, podem não ser esclarecedores dos pontos críticos de contaminação por Salmonella sp em granjas (Funk et al., 2001).

Desta forma, o objetivo deste estudo foi avaliar, em um sistema com isolamento anterior de Salmonella sp, a fase em que ocorreu a infecção e a soroconversão em um lote escolhido aleatoriamente e, paralelamente, identificar possíveis variações dos sorovares isolados nas diferentes fases de produção.

\section{MATERIAL E MÉTODOS}

$\mathrm{O}$ estudo foi realizado em duas fases. $\mathrm{Na}$ primeira fez-se um estudo transversal para a determinação da ocorrência de Salmonella sp em fêmeas de reposição em três unidades de produção de leitões (UPL) pertencentes a um sistema de produção situado no Rio Grande do Sul, onde havia sido encontrada elevada prevalência de suínos portadores ao abate (Bessa et al., 2004). Na segunda fase, uma das UPL da fase anterior foi escolhida para a realização do estudo longitudinal que acompanhou um lote de animais do nascimento até o abate. A escolha da UPL teve como critérios a ocorrência de animais excretores de Salmonella sp e a presença de um padrão de sanidade considerado médio em relação à totalidade das granjas integradas.

$\mathrm{Na}$ primeira fase, foram realizadas duas visitas ao setor de reposição de cada uma das três UPL, sendo colhidas amostras de fezes de todas as leitoas de reposição que chegavam à UPL no dia da visita e daquelas alojadas há 30 dias. Foram amostrados 125 animais, sendo as amostras processadas em pool de fezes colhidas de cinco animais.

Para a segunda fase, partiu-se de um número de amostras calculado a ser colhido na terminação, considerando-se uma população de 200 animais/lote de terminação, prevalência esperada de $30 \%$ (Kich, 2004), o pior resultado aceitável de \pm 10 pontos percentuais e intervalo de confiança de 95\% (EpiInfo, 2004). Para alcançar a amostra pré-determinada de 56 suínos, o número de animais a serem amostrados ao longo das fases foi ajustado. Quando utilizados suabes retais, aumentou-se em $80 \%$ o tamanho da amostra em virtude da menor sensibilidade dessa técnica, necessária para a colheita de fezes de leitões na maternidade e início da creche. $\mathrm{O}$ número de matrizes a serem amostradas foi determinado em função da programação de partos da UPL e visando garantir o fornecimento da quantidade necessária de leitões para o estudo. Ao abate, em virtude do maior número de materiais a serem colhidos de cada suíno, amostrou-se um subgrupo de animais.

O estudo longitudinal teve início com a avaliação bacteriológica e sorológica de fêmeas aos 100 dias de gestação $(\mathrm{n}=19)$. Aos 15 dias de lactação, um subgrupo das matrizes $(\mathrm{n}=15)$ foi novamente amostrado e 99 leitões, pertencentes às suas leitegadas (6-7 leitões/fêmea), foram incluídos no estudo. $\mathrm{O}$ acompanhamento na unidade de creche ocorreu em duas ocasiões: 10 dias após a chegada dos leitões na creche e 10 dias antes da saída deles para a terminação. Na primeira visita, foram amostrados os 99 leitões identificados na 
maternidade. Na segunda visita, quando foi possível colher maior quantidade de fezes do reto, foram amostrados 56 animais. Esses mesmos animais foram novamente amostrados após 10 dias da transferência para a unidade de terminação. Ao abate, foram amostrados 26 animais, sendo colhidas amostras individuais de conteúdo intestinal, linfonodos mesentéricos e sangue. Para a avaliação da contaminação cruzada das carcaças, foram utilizados cinco pools de suabes de carcaças provenientes do lote de origem dos animais avaliados.

Em todas as visitas, exceto na avaliação dos setores de reposição, realizou-se a pesquisa para a presença de Salmonella sp no piso das baias. A técnica empregada consistiu em uma modificação da técnica de suabe de arrasto. Adotou-se como suabe de arrasto um "pro-pé" (protetor de calçados de uso hospitalar) umedecido em água peptonada, fazendo-se uma caminhada por toda área da baia. Após, o suabe foi imediatamente imerso em $225 \mathrm{ml}$ de água peptonada tamponada. Realizaram-se três amostragens na fase de gestação, três na maternidade, oito na creche e quatro na terminação. $\mathrm{O}$ piso do caminhão que transportou os animais para o frigorífico foi amostrado uma vez, antes do embarque dos animais, por meio de um suabe de arrasto. A amostragem nas baias de espera do frigorífico foi realizada antes da entrada do lote dos animais do estudo, fazendose quatro suabes de arrasto.

Amostras foram colhidas de todos os lotes de ração fornecidos aos animais na reposição $(\mathrm{n}=2)$, gestação $(n=2)$, maternidade $(n=2)$, creche $(\mathrm{n}=10)$ e terminação $(\mathrm{n}=10)$, sendo mantidas congeladas até o processamento. As amostras de ração do período final de terminação foram processadas em triplicata.

Para o isolamento, foi seguido o protocolo testado por Michael et al. (2003), que consiste de etapas de pré-enriquecimento de $25 \mathrm{~g}$ de amostra em $225 \mathrm{ml}$ de água peptonada tamponada, enriquecimento seletivo em caldo tetrationato de Muller Kauffmann e em caldo Rappaport Vassiliadis, e isolamento em ágar verde brilhante-lactose-sacarose (BPLS) e ágar xilose lisina-tergitol 4 (XLT4). Os isolados foram confirmados por caracterização bioquímica e sorotipificação. As amostras de soro foram testadas pela utilização de um ELISA-LPS a partir de S. Typhimurium, desenvolvido pela Embrapa - CNPSA (Kich, 2004).

Os dados obtidos nas avaliações bacteriológica e sorológica foram analizados usando-se teste exato de Fisher (Statistical... 1998).

\section{RESULTADOS E DISCUSSÃO}

Do total de 25 pools coletados nas três UPL, oito (32\%) foram positivos para Salmonella sp. Das amostras positivas, quatro eram provenientes de leitoas alojadas há 30 dias na granja e quatro eram de leitoas de reposição, o que demonstra o constante risco de introdução desse microrganismo no sistema. É preciso considerar que a característica intermitência na excreção fecal do gênero Salmonella (Nielsen et al., 1995) permite supor que a média de animais positivos no grupo possa ser ainda maior que a encontrada. É interessante ressaltar que, pelo fato de as fezes coletadas terem sido processadas em pool de cinco amostras, de um até cinco animais excretores poderiam compor cada amostra positiva, podendo representar uma presença ainda mais elevada de animais portadores na UPL.

Das 19 fêmeas que foram amostradas no setor de gestação, 18 (94,7\%) eram positivas no ELISALPS. Não houve isolamento de Salmonella sp das amostras de fezes colhidas das fêmeas. Aos 15 dias de lactação, a soroprevalência do subgrupo amostrado reduziu-se para $66,7 \%$ (10/15), enquanto a análise bacteriológica evidenciou que duas fêmeas estavam excretando Salmonella sp nas fezes. A ausência de isolamento de Salmonella sp entre as fêmeas em gestação, embora apresentassem elevado índice de soropositividade (Tab. 1), pode ser atribuído ao fato de elas não estarem excretando a bactéria no momento da amostragem (Christensen e Rudemo, 1998) dada à característica intermitência (Nielsen et al., 1995). A redução de animais soropositivos constatada no grupo das matrizes, quando da amostragem realizada no setor de maternidade, mesmo não sendo estatisticamente significativa, pode estar relacionada à transferência de imunoglobulinas séricas para o colostro (Klobasa et al., 1985). 
Tabela 1. Salmonella sp em amostras de fezes e de sorologia em fêmeas alojadas nos setores de gestação e maternidade de uma unidade produtora de leitões do Rio Grande do Sul

\begin{tabular}{llccccc}
\hline & \multirow{2}{*}{$\mathrm{n}$} & \multicolumn{2}{c}{ Isolamento } & & \multicolumn{2}{c}{ ELISA } \\
\cline { 3 - 4 } \cline { 6 - 7 } & & Positivo & Negativo & & Positivo & Negativo \\
\hline Gestação & 19 & $0(0 \%)$ & $19(100 \%)$ & & $18(94,7 \%)$ & $1(5,3 \%)$ \\
Maternidade & 15 & $2(13,4 \%)$ & $13(86,6 \%)$ & & $10(66 \%)$ & $5(34 \%)$ \\
\hline
\end{tabular}

Ao contrário de outros estudos (Berends et al., 1996), nos quais as unidades de produção de leitões foram apontadas como responsáveis por até $10 \%$ das contaminações dos lotes por Salmonella sp, no presente estudo todos os leitões mantiveram-se negativos nos testes bacteriológico e sorológico durante o período de maternidade e creche. Dessa forma, a associação dos dois resultados ao longo das fases de maternidade e creche indica que não houve a contaminação dos leitões a partir da excreção de Salmonella sp detectada nas matrizes.
Após a transferência dos animais para a terminação, observou-se o aparecimento de animais positivos no lote. Os dados demonstram alta excreção (42/56) aos 10 dias após o alojamento dos animais na terminação (80 dias de idade), com posterior redução do isolamento a partir do conteúdo intestinal e linfonodos (5/26) ao abate (Tab. 2). Galland et al. (2000) também observaram a ocorrência de uma rápida diminuição no isolamento de Salmonella sp das fezes de animais positivos durante o período de terminação, alcançando índices menores que $1 \%$ aos 60 dias e não havendo mais isolamento ao abate.

Tabela 2. Distribuição percentual dos leitões, quanto ao resultado do isolamento de Salmonella e sorologia na terminação $(\mathrm{n}=56)$ e ao abate $(\mathrm{n}=26)$

\begin{tabular}{|c|c|c|c|c|c|c|}
\hline \multirow{3}{*}{ ELISA } & \multicolumn{3}{|c|}{ Terminação } & \multicolumn{3}{|c|}{ Abate } \\
\hline & \multicolumn{2}{|c|}{ Isolamento } & \multirow[b]{2}{*}{ Total } & \multicolumn{2}{|c|}{ Isolamento } & \\
\hline & Positivo & Negativo & & Positivo & Negativo & Total \\
\hline Positivo & 23,2 & 5,4 & $28,6 a$ & 11,5 & 65,4 & $76,9 b$ \\
\hline Negativo & 51,8 & 19,6 & $71,4 \mathrm{c}$ & 7,7 & 15,4 & $23,1 d$ \\
\hline Total & 75,0 & 25,0 & 100,0 & 19,2 & 80,8 & 100,0 \\
\hline
\end{tabular}

Valores seguidos por letras distintas na mesma linha diferem entre si $(\mathrm{P}<0,001)$.

Uma vez que o período necessário para atingir níveis detectáveis de anticorpos após a infecção é de, aproximadamente, duas semanas (van der Wolf et al., 2001b; van der Gaag et al., 2004), e considerando que o intervalo de tempo entre o alojamento dos animais na terminação e a amostragem foi de 10 dias, é possível compreender o ainda baixo número de animais com sorologia positiva encontrado nessa amostragem, caracterizando o período de soroconversão. Ao mesmo tempo, esse baixo índice de soropositivos pode ser interpretado como mais um indício que o momento de contaminação do lote ocorreu após o alojamento na granja terminadora. Ao abate, foi possível constatar o aumento da percentagem de animais soropositivos até $76,9 \%$ (20/26), demonstrando a intensa disseminação da infecção ocorrida no lote. Dos animais que haviam soroconvertido na terminação, dois voltaram a apresentar sorologia negativa ao abate. Essa observação está de acordo com estudos que relatam que, uma vez recuperado, o animal soropositivo pode vir a tornar-se negativo (van der Wolf et al., 2001a; van der Gaag et al., 2004).

O decréscimo no número de excretores de Salmonella sp, observado nas fezes ao abate, não deve minimizar a importância dos animais provenientes de lotes positivos que chegam ao frigorífico. Estudos realizados anteriormente (Rostagno et al., 2003) demonstraram a importância da contaminação cruzada de animais negativos que chegam ao frigorífico, a partir de animais portadores que estão excretando Salmonella sp nas fezes. A rápida invasão de linfonodos que ocorre a partir do trato gastrintestinal (Hurd et al., 2001) resulta em importante aumento no número de animais portadores na linha de abate. A entrada de 
animais positivos para Salmonella sp no frigorífico é considerada o principal fator de risco para a contaminação das carcaças e do produto final (Stege et al., 2001). Embora no presente estudo não tenha havido isolamento de Salmonella sp dos suabes de carcaça, estudos anteriores (Bandeira, 2003; Castagna et al., 2004), realizados no mesmo frigorífico, indicaram a associação da prevalência de animais portadores ao abate e a contaminação de cortes e embutidos do tipo frescal. Uma possível explicação para a ausência de isolamento neste estudo seria a adoção do suabe de superfície para a amostragem das carcaças, em contraste com os estudos anteriores (Bandeira, 2003; Castagna et al., 2004) que amostraram $25 \mathrm{~g}$ de produto. Apesar do suabe de carcaça ser o método comumente proposto para o controle de carcaças na linha de abate (Swanenburg et al., 2001), sabe-se que a menor quantidade amostrada pode influir diretamente no sucesso do isolamento.

Isolou-se Salmonella sp de 7,7\% (2/26) das amostras de ração, sendo o nível de contaminação encontrado bastante próximo àquele descrito por Fialho et al. (1985), no qual $5,8 \%$ de amostras de ingredientes e rações foram positivas. Todas as amostras positivas eram provenientes do período final da terminação $(2 / 10)$, quando o processamento foi realizado em triplicata. Assim, esses resultados demonstram as melhores chances de isolamento quando utilizado um maior número de repetições, como já descrito (Hurd et al., 2002). Isto fica evidenciado, uma vez que das 15 alíquotas retiradas de cinco amostras de ração analisadas, apenas três apresentaram isolamento. Numa das amostras positivas houve isolamento em apenas uma das alíquotas processadas, enquanto na outra amostra duas alíquotas foram positivas.

Das 18 amostras de ambiente, apenas as quatro provenientes da terminação foram positivas, coincidindo com o pico de excreção nos animais. A amostragem realizada no caminhão que transportou os animais ao abate resultou em ausência de isolamento de Salmonella sp Entretanto, em estudos anteriores, observou-se que apenas um número reduzido de suabes coletados em caminhões são positivos. Um exemplo disso é o resultado obtido por FedorkaCray et al. (1997), quando houve o isolamento de Salmonella sp em apenas 0,7\% dos 549 suabes realizados em caminhões de transporte. No monitoramento das baias de espera, os suabes coletados apresentaram 25\% (1/4) de resultados positivos (Tab. 3). Estudos recentes (Hurd et al., 2001) mostraram que a infecção de suínos expostos ao ambiente contaminado por Salmonella sp pode ocorrer após um período de apenas duas horas. Com isso, o ambiente de espera nos frigoríficos constitui-se num ponto crítico de controle para reduzir a contaminação ao abate e no processamento.

Tabela 3. Sorovares de Salmonella das amostras isoladas nas diferentes fases, ao abate, no ambiente e na ração do sistema avaliado

\begin{tabular}{lccccc}
\hline Reposição & Maternidade & Terminação & Abate & Ambiente & Ração \\
\hline Bredeney & Typhimurium & Typhimurium & Typhimurium & Typhimurium & Senftenberg \\
Derby & Tennessee & Senftenberg & Senftenberg & Panama $^{2}$ & \\
\hline
\end{tabular}

${ }^{1}$ Baias da terminação; ${ }^{2}$ Baias de esperea do frigorífico.

O sorovar Typhimurium foi encontrado em todos os animais da terminação com isolamento positivo; dois animais tiveram isolamento concomitante do sorovar Senftenberg. Os sorovares Typhimurium e Tennessee foram encontrados nas fezes de matrizes na maternidade. Davies (1998), por ter encontrado o mesmo sorovar de Salmonella sp em leitões e em fêmeas alojadas na maternidade, apontou como provável a contaminação dos leitões antes da transferência para a creche. No presente trabalho, entretanto, o não isolamento de Salmonella sp e a sorologia negativa ao longo das fases de maternidade e creche indicam que não houve a transmissão de Salmonella para os leitões a partir das matrizes.

Embora a escolha das colônias caracterize um fator limitante na avaliação da variabilidade, a identificação dos mesmos sorovares já encontrados nos animais na terminação quando do abate, reforça a importância dessa fase na contaminação do lote acompanhado. Ao abate, os sorovares Typhimurium e Senftenberg foram 
encontrados em três e dois animais, respectivamente. As amostras isoladas a partir de conteúdo intestinal apresentaram apenas o sorovar Typhimurium, enquanto aquelas isoladas de linfonodos apresentaram tanto o sorovar Senftenberg, quanto o sorovar Typhimurium. O sorovar Senftenberg, recuperado dos animais na terminação e ao abate, foi o mesmo isolado das amostras de ração, indicando a possível relação do consumo de ração contaminada no setor de terminação com a introdução de Salmonella sp nesse sistema. Apesar de Rostagno et al. (2003) terem encontrado $25 \%$ de suínos abatidos portadores dos mesmos sorovares de Salmonella isolados nas baias de espera, no presente estudo o sorovar identificado nas baias de espera (Panama) diferiu daquele identificado nos animais após o abate. Embora nesse caso não tenha sido possível relacionar a interferência da microbiota das baias de espera na prevalência do lote examinado, cabe lembrar que em lotes que chegam positivos no frigorífico é a granja que ocupa papel mais importante no ciclo de contaminação, enquanto a baia de espera assume importância na contaminação dos lotes provenientes de granjas negativas (Swanenburg et al., 2001).

\section{CONCLUSÕES}

A presença de fêmeas soropositivas e que excretam Salmonella $\mathrm{sp}$ nas fezes não determinou a infecção dos leitões no lote acompanhado, tendo sido a fase de terminação o ponto crítico na difusão da infecção e a ração um dos possíveis veículos de contaminação dos animais. Durante a fase de terminação e ao abate foram identificados animais soropositivos e que excretam Salmonella sp, sendo o sorovar Typhimurium o mais prevalente. Tanto no ambiente da granja, como nas baias de espera do frigorífico havia a presença de Salmonella sp.

\section{AGRADECIMENTOS}

À Dra. Eliane Falavina dos Reis, Departamento de Bacteriologia, Instituto Oswaldo Cruz, pela sorotipificação das amostras.

\section{REFERÊNCIAS BIBLIOGRÁFICAS}

BANDEIRA, R. Presença de Salmonella sp em suínos ao abate e em cortes de pernil processados em frigorífico do Rio Grande do Sul. 2003. $74 f$. Dissertação (Mestrado) - Faculdade de Agronomia, Universidade Federal do Rio Grande do Sul, Porto Alegre.

BERENDS, B.R.; URLINGS, H.A.P.; SNIJDERS, J.M.A. et al. Identification and quantification of risk factors in animal management and transport regarding Salmonella spp. in pigs. Int. J. Food Microbiol., v.30, p.3753,1996 .

BESSA, M.C.; COSTA, M.; CARDOSO, M. Prevalência de Salmonella sp em suínos abatidos em frigoríficos do Rio Grande do Sul. Pesq. Vet. Bras., v.24, p.80-84, 2004.

CASTAGNA, S.M.F.; SCHWARZ, P.; CANAL, C.W. et al. Prevalência de suínos portadores de Salmonella ao abate e contaminação de embutidos frescal. Acta Sci. Vet., v.32, p.141147, 2004.

CHRISTENSEN, J.; RUDEMO, M. Multiple change-point analysis applied to the monitoring of Salmonella prevalence in Danish pigs and pork. Prev. Vet. Med., v.36, p.131-143, 1998.

DAVIES, P.R. Spatial patterns of fecal shedding of Salmonella by pigs housed in buildings with open-flush gutters. Swine Health Prod., v.6, p.101-106, 1998.

EPI-INFO versão.3.2.2. [s.1.]: Organização Mundial da Saúde, 2004.

FEDORKA-CRAY, P.; HOGG, A.; GRAY, J.T. et al. Feed and feed trucks as sources of Salmonella contamination in swine. Swine Health Prod., v.5, p.189-193, 1997.

FIALHO, E.T.; SOBESTIANSKY, J.R.F.; BRITO, J.R.F. et al. Análise proximal $e$ ocorrência de Salmonelas em alimentos $e$ concentrados protéicos utilizados em rações de suínos. Concórdia Embrapa/CNPSA, 1985. p.14. (Comunicado Técnico, n. 87)

FUNK, J.A.; DAVIES, P.R.; NICHOLS, M.A. Longitudinal study of Salmonella enterica in growing pigs reared in multiple-site swine production systems. Vet. Microbiol., v.83, p.4560, 2001 . 
GALLAND, J.C.; HOUSE, J.K.; HYATT, D.R. et al. Prevalence of Salmonella in beef feeder steers as determined by bacterial culture and ELISA serology. Vet. Microbiol., v.76, p.143$151,2000$.

HURD, H.S.; GAILEY, J.K.; MCKEAN, J.D.et al. Experimental rapid infection in market swine following exposure to a Salmonella contaminated environment. Berl. Munch. Tierarztl. Wocheschr., v.114, p.382-384, 2001.

HURD, H.S.; MCKEAN, J.D.; GRIFFITH, R.W. et al. Salmonella enterica infections in market swine with and without transport and holding. Appl. Environ. Microbiol., v. 68, p.2375-2381, 2002.

KICH, J.D. Desenvolvimento de um teste de ELISA-LPS para Salmonella e sua aplicação em rebanhos suínos na identificação de fatores de risco associados à infecção. 2004. 114f. Tese (Doutorado) - Faculdade de Veterinária, Universidade Federal do Rio Grande do Sul, Porto Alegre.

KLOBASA, F.; HABE, F.; WERHAHN, E. et al. Changes in the concentrations of serum IgG, IgA and IgM of sows throughout the reproductive cycle. Vet. Immunol. Immunopathol., v.10, p.341-353, 1985.

MICHAEL, G.B.; CARDOSO, M.; COSTA, M. Comparison of different selective enrichment steps to isolate Salmonella sp from feces of finishing swine. Braz. J. Microbiol., v.34, p.138142, 2003.

NIELSEN, B.; BAGGESEN, D.; BAGER, F. et al. The serological response to Salmonella serovar Typhimurium and Infantis in experimentally infected pigs. The time course followed with an indirect anti-LPS ELISA and bacteriological examinations. Vet. Microbiol., v.47, p.205-218, 1995.

ROSTAGNO, M.H.; HURD, H.S.; MCKEAN J.D. et al. Preslaughter holding environment in pork plants is highly contaminated with Salmonella enterica. Appl. Environ. Microbiol., v.69, p.4489-4494, 2003.

STÄRK, K.D.C.; WINGSTRAND, A.; DAHL, J. et al. Differences and similarities among experts' opinions on Salmonella enterica dynamics in swine pre-harvest. Prev. Vet. Med., v.53, p.7-20, 2002.

STATISTICAL Package for the Social Sciences. Version 8.0. Chicago: McGraw-Hill Book, 1998.

STEGE, H.; CHRISTENSEN, J.; NIELSEN, J.P. et al. Prevalence of subclinical Salmonella enterica infection in Danish finishing pig herds. Prev. Vet. Med., v.44, p.175-188, 2000.

STEGE, H.; CHRISTENSEN, J.; NIELSEN, J.P. et al. Data-quality issues and alternative variablescreening methods in a questionnaire-based study on subclinical Salmonella enterica infection in Danish pig herds. Prev. Vet. Med., v.48, p.35-54, 2001.

SWANENBURG, M.; URLINGS, H.A.P.; SNIJDERS, J.M.A. et al. Salmonella in slaughter pigs: prevalence, serotypes and critical control points during slaughter in two slaughterhouses. Int. J. Food Microbiol., v.70, p.243-254, 2001.

van der GAAG, M.A.; VOS, F.; SAATKAMP, H.W. et al. A state-transition simulation model for the spread of Salmonella in the pork supply chain. Europ. J. Oper. Res., v.156, p.782-798, 2004.

van der WOLF, P.J.; van SCHIE, F.W.; ELBERS, A.R.W. et al. Administration of acidified drinking water to finishing pigs in order to prevent Salmonella infections. Vet. Q., v.23, p.121-125, 2001a.

van der WOLF, P.J.; WOLBERS, W.B.; ELBERS, A.R. et al. Herd level husbandry factors associated with the serological Salmonella prevalence in finishing pig herds in The Netherlands. Vet. Microbiol., v.78, p.205219, $2001 b$. 